\title{
Sexual Maturity-Dependent Changes in Neuronal Morphology in the Prepacemaker Nucleus of Adult Weakly Electric Knifefish, Eigenmannia
}

\author{
Günther K. H. Zupanc ${ }^{1-3}$ and Walter Heiligenberg ${ }^{1,2}$ \\ 'Department of Neurosciences, School of Medicine, and ${ }^{2}$ Neurobiology Unit, Scripps Institution of Oceanography, \\ University of California at San Diego, La Jolla, California 92093, and ${ }^{3}$ Neural Systems Laboratory, The Salk Institute and \\ Howard Hughes Medical Institute, La Jolla, California 92037
}

Knifefish of the genus Eigenmannia (Gymnotiformes, Teleostei) are seasonal breeders that spawn only during the tropical rainy season. Both sexes modulate their otherwise constant wave-like electric organ discharges (EODs) in the context of courtship and aggressive behavior by "chirps," abrupt frequency modulations with brief interruptions. Playbacks of recordings of male courtship chirps can induce spawning in gravid females (Hagedorn and Heiligenberg, 1985).

The EOD, produced by a specialized electric organ, is under the control of a pacemaker nucleus (Pn) in the medulla oblongata. Injections of HRP into the Pn label only a small cluster of cells bilaterally at the boundary of diencephalon and mesencephalon, constituting the prepacemaker nucleus, PPn (Heiligenberg et al., 1981). Microstimulation experiments have shown that chirp-like EOD modulations can be elicited from a subnucleus of the PPn, the PPn-C (Kawasaki and Heiligenberg, 1988; Kawasaki et al., 1988).

By retrograde HRP labeling, we investigated the dependence of the PPn's morphology upon the sexual maturity of the fish. The most prominent effect was that, during the breeding season, females developed an abundance of "varicosities," swellings 1-4 $\mu \mathrm{m}$ in diameter in distal regions of dendrites at a density of approximately $1 / 10 \mu \mathrm{m}$. In contrast to mature females, immature females had none or only a few varicosities. Such a clear correlation between the abundance of varicosities and relative gonadal weight was not found in males, most likely because testicular and dendritic development are not strictly synchronized. After the onset of the simulated dry season, however, relative gonadal weight, as well as the number of varicosities, was reduced drastically in both sexes. This reduction in the number of varicosities is accompanied by a decrease in their diameter.

\footnotetext{
Received Nov. 8, 1988; revised Mar. 14, 1989; accepted Mar. 15, 1989.

We thank Marianne Altstetter, Grace Kennedy, Peggy Leong, and Georgia Malan for excellent technical assistance. Dr. R. Glenn Northcutt from the Neurobiology Unit of the Scripps Institution of Oceanography, La Jolla, kindly provided the photomicroscope, and Dr. Larry W. Swanson from the Salk Institute, La Jolla, the Magiscan computer imaging system. We also thank Drs. James T. Enright, Masashi Kawasaki, Clifford H. Keller, and Gary J. Rose for helpful suggestions concerning the manuscript. This work was supported by a doctoral fellowship from the Friedrich Ebert-Foundation, Bonn (FRG) to G.K.H.Z., and NIMH Grant 2R01 MH26149-13 to W.H.

Correspondence should be addressed to Günther K. H. Zupanc, Scripps Institution of Oceanography, Neurobiology Unit, A-002, University of California at San Diego, La Jolla, CA 92093.

Copyright (C) 1989 Society for Neuroscience $0270-6474 / 89 / 113816-12 \$ 02.00 / 0$
}

Varicosities may represent growing buds or regions of synaptic input from afferent areas or both. Reconstruction of individual PPn-C neurons showed maturity-dependent changes in the pattern of dendritic proliferation in females. Such dynamic changes in the structure of neurons might subserve seasonal modifications in an animal's propensity to execute specific behaviors.

South American knifefish of the genus Eigenmannia (Gymnotiformes, Teleostei) produce continuous, wave-like electric organ discharges (EODs) at very stable but individually different frequencies in the range of $250-600 \mathrm{~Hz}$. In the context of social communication, however, their EODs can be modulated. "Chirps" are a very common form of modulations: abrupt frequency modulations that may lead to a brief interruption of the EOD for several cycles. Short chirps, $40 \mathrm{msec}$ on the average, are produced during agonistic encounters, while longer chirps, $90 \mathrm{msec}$ on the average, are common during courtship (Hopkins, 1974; Hagedorn and Heiligenberg, 1985). Chirps are produced by both sexes but are most frequently and most strongly emitted by dominant males during aggression, courtship, and mating. During the night of spawning, a male may chirp up to $60-80$ times/min.

Each EOD is driven by a single command spike from the medullary pacemaker nucleus, Pn (Bennett, 1971). The pacemaker appears to be exclusively innervated by the prepacemaker nucleus (PPn), a bilateral cluster of neurons at the boundary of the diencephalon and mesencephalon (Heiligenberg et al., 1981).

On the basis of anatomical and physiological studies, the PPn has been subdivided into a dorsomedial and a ventrolateral subnucleus (Kawasaki and Heiligenberg, 1988; Kawasaki et al., 1988; Rose et al., 1988). Since L-glutamate stimulation of the ventrolateral subnucleus elicits an abrupt form of EOD modulation resembling the "chirps" observed in natural courtship, it was named "PPn-C" (Kawasaki et al., 1988). Intracellular stimulation and injection of Lucifer yellow have shown that chirps are triggered by firing of large multipolar neurons of the PPn-C (Kawasaki and Heiligenberg, 1988).

Gonadal recrudescence and breeding in gymnotiform fish are induced by the conditions of the tropical rainy season, i.e., a rise in water level, dilution of the water, and occasional rain. Gonads regress during the intervening dry seasons (Hopkins, 1974). These seasonal conditions can readily be simulated to breed such fish in captivity, and variations in the light-dark cycle are not required to induce gonadal recrudescence (Kirsch- 
baum, 1975, 1979). Casual observations suggested that the large multipolar cells of the PPn-C have more extensive dendrites in animals with developed gonads, hereafter referred to as "sexually mature" animals. Similar maturity-dependent changes in the morphology of brain structures involved in the control of song behavior have been reported in birds (for review, see Arnold, 1985; DeVoogd, 1986; Nottebohm, 1986; Nottebohm et al., 1987). Our preliminary findings appeared to be in accordance with the observation that chirps are exclusively produced in the context of aggression and courtship. Therefore, we set out to study the morphology of these neurons quantitatively in order to explore its dependence upon sexual maturity. Such an investigation appeared to be especially interesting since Eigenmannia is a seasonal breeder, spawning only during the rainy season (Hopkins, 1974).

Preliminary results of this investigation have previously been reported in the form of abstracts (Zupanc and Heiligenberg, 1988a, b).

\section{Materials and Methods}

Maintenance of animals. We used 97 knifefish of the genus Eigenmannia (probably $E$. lineata) of various total lengths $(88-280 \mathrm{~mm}$ ) and body weights $(1.15-33.7 \mathrm{gm})$. They were purchased from tropical fish importers or raised in our laboratory. We kept these fish in large glass or clear acrylic, $200-800$ liter tanks at temperatures of $24-28^{\circ} \mathrm{C}$ and $\mathrm{pH}$ values of 4-7. They were fed daily on tubificid worms. Some animals, especially females, enlarged their gonads on this high-protein diet. The transparency of Eigenmannia made it possible to judge the developmental state of the gonads in intact specimens. Systematic growth of gonads, mating, and spawning were induced by imitating the tropical rainy season (Kirschbaum, 1975, 1979). Each day deionized water was added to the aquarium so that the water level rose by $1-5 \mathrm{~cm}$. When the water reached the top of the aquarium, the level was lowered by approximately $50 \%$. Clock-controlled pumps sprinkled water on the surface of the aquarium for $3 \mathrm{hr}$ every $6 \mathrm{hr}$. Daily addition of deionized water raised the resistivity of the aquarium water from approximately $1 \mathrm{k} \Omega \cdot \mathrm{cm}$ to $10-20 \mathrm{k} \Omega \cdot \mathrm{cm}$ in the course of a few weeks. The simulation of the rainy season was terminated and the simulation of the dry season started by discontinuing the sprinkler system and the addition of deionized water. As a consequence, the electrical resistivity gradually sank again over the course of several weeks. At all times, the photoperiod was held constant at a $12 \mathrm{hr}$ light-12 hr dark cycle by means of a timer. Termination of the rainy season conditions led to gonadal regression over the course of several weeks.

HRP labeling. Neurons of the PPn-C were labeled retrogradely after injection of HRP into the medullary Pn. Unconjugated HRP has been shown to label only the somata and dendrites of the multipolar neurons of the PPn-C (Kawasaki et al., 1988). Individual fish were immobilized through intramuscular injection of approximately $1 \mu \mathrm{g}$ Flaxedil (gallamine triethiodide, Davis + Geck)/gm body weight or through anesthesia in a $0.5 \%$ urethane (ethyl carbamate, Sigma Chemical Co.) solution. The amount of Flaxedil or the time the fish remained in the urethane solution was chosen to be just sufficient to suppress bodily movements. In the course of the experiments, application of urethane turned out to be more effective since the fish recovered reliably and very fast.

In the tank designed for surgery and HRP injections, the animal's body was held in a clamp, lined with soft sponges, so that only the upper surface of the head stuck out of the water. Special attention was given not to stress the fish because full recovery from the operation was ensured only without abrasion or damage to the skin. By means of a tube inserted into the mouth, the fish was respirated by a constant flow of aerated water at the same temperature $\left(27-28^{\circ} \mathrm{C}\right.$ ), resistivity (approximately $4 \mathrm{k} \Omega \cdot \mathrm{cm}$ ), and $\mathrm{pH}(7)$ as the surrounding water. For urethane anesthesia, urethane was added to the bath water to achieve a final concentration of $0.5 \%$. Although Flaxedil strongly attenuated the EODs, residual discharges and the spinal command signal $(50 \mu \mathrm{V}-2$ $\mathrm{mV}$ ) could still be monitored with a suction electrode fitted over the tip of the tail.

A small midline incision was made in the cartilaginous tissue above the caudal portion of the corpus cerebelli to reach the $\mathrm{Pn}$, which is located in the medulla oblongata at a vertical depth of approximately
2-3 mm. A recording glass capillary electrode (inner diameter about 10 $\mu \mathrm{m}$ ) containing a $3 \mathrm{M} \mathrm{NaCl}$ solution was used to determine the location of the pacemaker. The center of the nucleus could readily be recognized by the maximum of its field potential, which is phase-locked to the EOD. After the center had been determined, the electrode was retracted. A second electrode, consisting of 3 barrels, was then introduced in the same location: one barrel filled with $3 \mathrm{M} \mathrm{NaCl}$ and 2 barrels containing unconjugated HRP (type VI, Sigma Chemical Co., approximately $10 \%$ in $0.1 \mathrm{M}$ Tris buffer, $\mathrm{pH} 7.6$ ). After confirming the correct position of the tip of the triple-barrel electrode on the basis of a maximal pacemaker field potential, HRP was iontophoretically injected by applying a positive direct current of $1-8 \mu \mathrm{A}$ with reference to the ground electrode. The injection into the Pn could be recognized by an immediate rise of the pacemaker discharge frequency and, occasionally, by a complete shut-off of firing. We chose to inject HRP over a longer period of time whenever frequent clogging of the electrode suggested poor transport. After a total injection time of 5-25 min, the electrode was retracted, the wound was dried, and the cut in the cartilage was sealed with tissue glue (Histoacryl from Braun or Vetbond from 3M). As soon as the fish had recovered, it was transferred to a holding tank and kept there for $3-4 \mathrm{~d}$.

Under deep anesthesia by MS 222 (3-aminobenzoic acid ethyl ester, Sigma Chemical Co.), the fish was intracardially perfused with Hickman's Ringer containing $66.7 \mathrm{mg} /$ liter heparin sodium salt (Sigma Chemical Co.), $1 \mathrm{gm} /$ liter $\mathrm{NaNO}_{2}$, and $10 \mathrm{ml} /$ liter $2 \%$ Xylocaine (Astra Pharmaceutical Products), pH approximately 6.8, followed by a perfusion with a fixative solution of $2 \%$ paraformaldehyde and $2 \%$ glutaraldehyde in $0.1 \mathrm{M}$ phosphate buffer ( $\mathrm{pH}$ 7.2). After a fixation time of $30 \mathrm{~min}$, the brain was removed from the skull, the right tectum was marked by a cut, and the tissue was postfixed in the fixative solution for $2 \mathrm{hr}$. The brain was transferred to phosphate buffer and placed in the refrigerator $\left(4^{\circ} \mathrm{C}\right)$ overnight.

Brains were sectioned on a vibratome (Lancer, series 1000) in the transverse plane at $50 \mu \mathrm{m}$. The HRP was detected histochemically by using a modified procedure described by Metcalfe (1985), based on a combination of a heavy-metal intensification reaction (Adams, 1981) and a glucose-glucose oxidase reaction mixture (Lundquist and Josefsson, 1971): the sections were presoaked for $15 \mathrm{~min}$ in $50 \mathrm{ml} 0.1 \mathrm{M}$

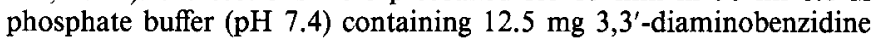
tetrahydrochloride (Sigma Chemical Co.) dissolved in $1 \mathrm{ml}$ distilled water, $20 \mathrm{mg}$ ammonium chloride, $1.25 \mathrm{ml}$ of $1 \%$ cobalt chloride, and $1 \mathrm{ml}$ of $1 \%$ nickel ammonium sulfate. The sections were incubated for 15-30 additional minutes after adding $100 \mathrm{mg} \beta-\mathrm{D}(+)$-glucose and 50 $\mu$ l glucose oxidase (Sigma Chemical Co.). After washing the tissue 3 times in $100 \mathrm{ml} 0.1 \mathrm{~m}$ phosphate buffer ( $\mathrm{pH} \mathrm{7.4)}$ for $3 \mathrm{~min}$ each, the scctions wcre mounted in scrial order on subbed slides, air-dried, counterstained with Neutral red, washed in distilled water, dehydrated in ethanols, cleared in Histo-Clear (National Diagnostics) and xylene, and mounted in Permount (Fisher Scientific Co.).

Measurements and data analysis. After perfusion of the fish, its length and body and brain weights were measured. The sex was determined by gonadal inspection, and the fresh weight of the testes in males and of the ovaries in females was assessed. Through these data, a maturity coefficient (MC) was determined for each fish:

$$
\mathrm{MC}=\frac{\text { fresh weight of gonads }}{\text { body weight }}
$$

Fresh weight was used instead of dry weight because, in some animals, the gonads were examined histologically after autopsy. In the remaining fish, fresh weight and dry weight of the gonads were highly positively correlated (Spearman's rank correlation coefficient $r_{s}=0.954, n=33$, $p<0.0001,2$-tailed).

To analyze the structure of the PPn, each section through the PPn region of the brain was cxamined bilaterally under the microscope. While tracing neuronal processes, axons and dendrites could not always be distinguished with certainty (Kawasaki et al., 1988), particularly at the caudal end of the PPn where axons and ventral dendrites intermingle extensively. Therefore, we measured all processes regardless of their identity and terminated our measurement at "the caudal end" of the PPn, defined as that section from which on all HRP-filled processesapparently axons-began to run in a caudoventral direction in parallel bundles. Some uncertainty in this definition did not significantly affect the overall length of the processes measured in the PPn: the total length of the bilateral processes in the most caudal section evaluated never 
contributed more than approximately $4 \%$ to the total length of all PPn processes measured in a particular brain.

HRP-filled somata and processes were drawn at a magnification of $250 \times$ with a camera lucida. Swellings on processes, referred to as "varicosities," were counted and their maximal lateral widths measured at $1000 \times$ under oil immersion. The lengths of the processes were computed from their ink drawings in single sections with a Magiscan computer imaging system (Joyce Loebl Nikon) and software written by $D$. Brittain (Salk Institute, La Jolla).

For normalization purposes, we measured the distance from the dorsal surface of the torus longitudinalis to the ventral boundary of the brain in each section through the PPn region and calculated an average vertical brain diameter. We chose the torus longitudinalis as a dorsal reference point instead of the cerebellum since the latter, due to its positively allometric growth (Leyhausen et al., 1987), varies extensively in the thickness and rostral extent among fish of different sizes and ages. The normalization of the lengths of the neuronal processes in the PPn was exccutcd in 2 steps: (1) The overall length of the processes in the PPn was divided by the number of somata filled sufficiently with HRP to reveal dendrites and then (2) this average total length of the dendritic arbor of one PPn cell body was divided by the average vertical brain diameter in the PPn region. The purpose of the first normalization procedure was to gain a measure of dendritic lengths independent of the number of cell bodies filled with HRP. The rationale for the second normalization procedure was that the vertical midline diameter of the brain in the PPn region is independent of sexual maturity changes but subject to the same shrinkage due to histological artifacts as the PPn. In addition, males showed a positive correlation between the brain diameter and the length of the neuronal processes $\left(r_{s}=0.500, n=8\right.$, not significant). By normalizing the length of their neuronal processes in reference to the brain diameter, we tried to obtain a brain sizeindependent measure of dendritic length. A positive correlation between brain size and dendritic length was not found in females $\left(r_{s}=-0.116\right.$, $n=6$, not significant).

Statistics. The data were evaluated by means of the program SYSTAT (version 4.0; Systat Inc.) on a Zenith Z-150 personal computer (Zenith Data Systems Corporation). Only nonparametric statistical methods (Siegel, 1956) were used.

\section{Results}

\section{Morphology of the PPn}

The PPn of Eigenmannia lies bilaterally at the boundary of diencephalon and mesencephalon, its cell bodies located 250 $500 \mu \mathrm{m}$ lateral from the midline and $400-700 \mu \mathrm{m}$ ventral from the center of the posterior commissure (Fig. 1). The structures surrounding the PPn have been identified by Kawasaki et al. (1988). In order to be able to assess individual neurons in detail, we tried to label only a few PPn neurons by injecting small amounts of HRP into the pacemaker. As a consequence, usually only somata of the ventrolateral subnucleus, PPn-C, were stained. The smaller, spindle-shaped cell bodies of the dorsomedial subnucleus were only labeled in cases with large HRP injections and good retrograde transport. These heavily labeled cases suggest that the PPn-C consists of approximately 100 neurons unilaterally, which is in agreement with earlier counts by Kawasaki et al. (1988). Most of the somata of this subnucleus are of the multipolar type (Fig. 2). Their 2-dimensional projections vary from circular to triangular or rectangular. Their maximal diameter is typically near $10 \mu \mathrm{m}$ but can reach $17 \mu \mathrm{m}$.

A small percentage of the neurons in the PPn-C appears to be of the bipolar type. These cells are ovoid in shape, their major axis being approximately $10 \mu \mathrm{m}$ long and their minor axis approximately $7 \mu \mathrm{m}$. Axon and dendrite originate from the opposite ends of the major axis.

In the multipolar neurons of the PPn-C, usually 2-3 thick principal dendritic trunks originate from the cell body. They may give rise to a few secondary and tertiary branches. Very often the processes bifurcate very close $(<10-20 \mu \mathrm{m})$ to the cell body. In some cases one cannot decide whether both branches originate separately from the soma or whether they bifurcate after the principal trunk has emerged. Counting such branches separately, we found as many as 6 dendritic processes in some neurons.

The dendrites extend beyond the nuclear boundary defined by the cluster of cell bodies; the PPn thus represents an "open nucleus" (Mannen, 1966). Dendrite diameters shrink from approximately $2 \mu \mathrm{m}$ in the proximal region to less than $0.5 \mu \mathrm{m}$ in the distal branches.

Reconstruction of 13 individual cells in 11 females (total lengths between 88 and $155 \mathrm{~mm}$, body weights between 1.2 and $11.2 \mathrm{gm}$, brain weights between 0.025 and $0.048 \mathrm{gm}$ ) revealed a total length of the dendritic arbor of up to $3000 \mu \mathrm{m}$ per multipolar neuron. In accordance with earlier findings (Kawasaki et al., 1988), we could define 3 dendritic territories (Fig. 2A): a ventral territory with dendrites extending ventral and caudal to the cell body; a dorsolateral territory with dendritic branches dorsolateral to the soma; and a dorsomedial territory stretching dorsomedially and rostrally towards the third ventricle. Some neurons did not show well-developed dorsolateral and dorsomedial dendritic fields, whereas they always displayed extensive dendrites in the ventral territory ( $c f$. Fig. $2 A$ and $2 B$ ). The extent of the dorsomedial dendritic territory appears to depend specifically upon the maturity of the fish (see below, "Reconstruction of individual neurons"), while the extent of all 3 territories appears to increase with the size of the animals. Individual dendrites both of the ventral and the dorsolateral territory extended as far as approximately $350 \mu \mathrm{m}$ from the cell body, and dendritic branches of the dorsomedial territory reached as far as $450 \mu \mathrm{m}$.

The somata and the dendrites of the multipolar cells are smooth and lack dendritic spines. Especially in mature fish (see below), however, the dendrites may show swellings ("varicosities") 1$4 \mu \mathrm{m}$ in diameter and 3-10 $\mu \mathrm{m}$ in length (Fig. 3). The typical density of such swellings is approximately 1 varicosity $/ 10 \mu \mathrm{m}$ dendritic length, but the maximum may be as high as 1 varicosity $/ 5 \mu \mathrm{m}$ dendritic length. Varicose dendrites appear to occur only in distal regions. Usually we did not find swellings on proximal parts of dendrites, less than $50 \mu \mathrm{m}$ from cell body.

The characteristics of the PPn efferents and their course to the pacemaker have already been described (Heiligenberg et al., 1981; Kawasaki and Heiligenberg, 1988; Kawasaki et al., 1988).

\section{Abundance of varicosities as a function of sexual maturity}

Simulation of the rainy season is known to induce gonadal growth in both sexes (Kirschbaum, 1975, 1979). Only a single female out of several tens could not be stimulated to develop her ovaries even after being exposed to rainy-season conditions for months. This fish was at least 2 years old and showed other signs of senility. It had been gravid on earlier occasions but had not spawned. On the other hand, the simulation of the rainy season is not a necessary prerequisite for gonadal recrudescence in captivity; some animals develop big gonads under dry-season conditions as long as they are fed on a high-protein diet.

In order to determine differences in the density of varicosities between mature and immature animals, we analyzed the PPn-C bilaterally according to the following 2 measures: (1) the number of varicosities per cell body and (2) the number of varicosities per $1 \mathrm{~mm}$ dendritic length. The first was obtained by counting all varicosities in the PPn-C and dividing this value by the number of labeled somata. The second was obtained by counting 


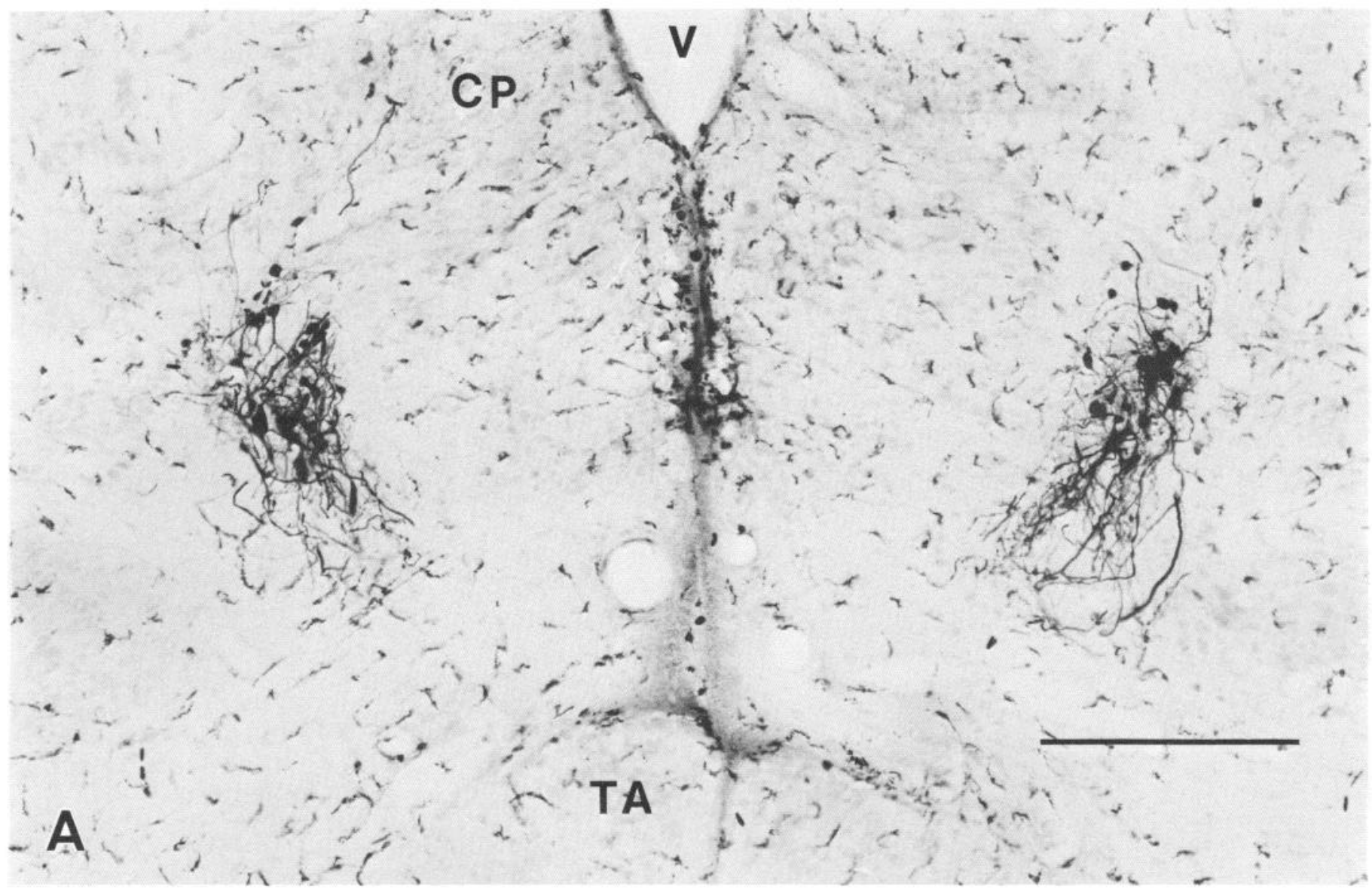

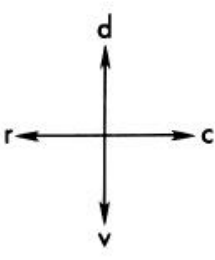

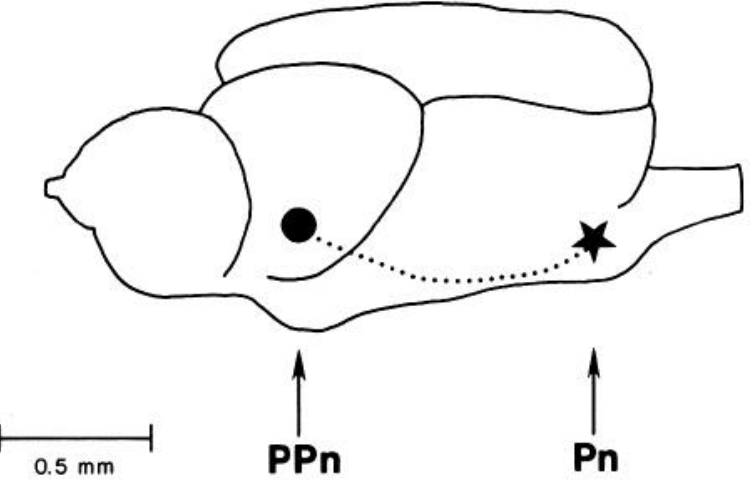

B injection into the pacemaker nucleus $(P n)$ of Eigenmannia. $A$. Transverse section $(50 \mu \mathrm{m})$ at the level of the PPn. $C P$, central posterior nucleus; $T A$, nucleus tuberis anterior; $V$, third ventricle. $B$, Side view of the brain of Eigenmannia showing diencephalic PPn and medullary Pn. $C$, Single large multipolar neuron labeled with HRP in a $50 \mu \mathrm{m}$ transverse section. Scale bars in $A$ and $C, 200 \mu \mathrm{m}$. 

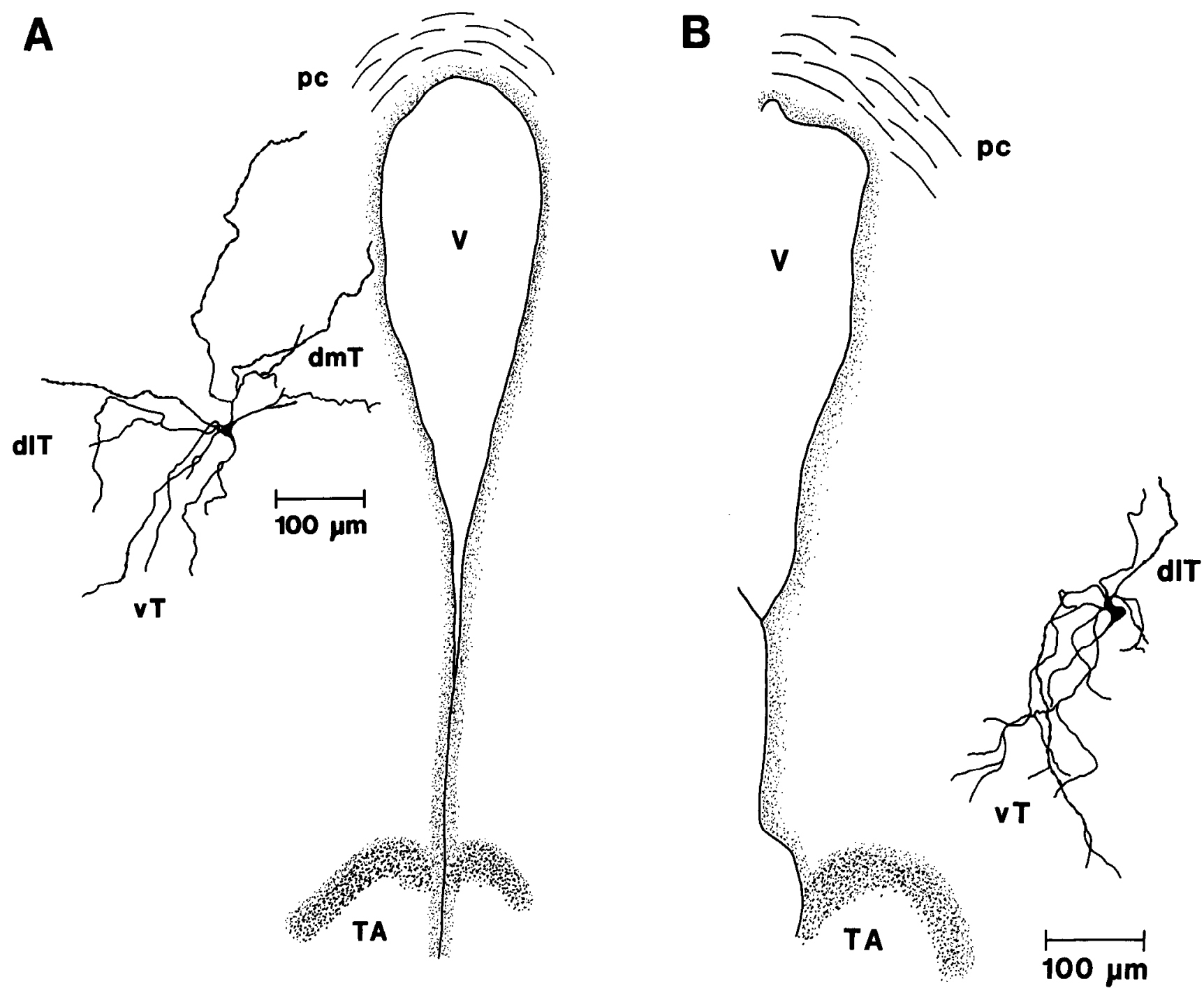

Figure 2. Sexual maturity-related differences in the morphology of the multipolar ncurons of the PPn in Eigenmannia. A, Camcra lucida drawing of dendritic morphology commonly found in sexually mature females. Note large dendrites extending into 3 separate territories, dorsomedially $(d m T)$, dorsolaterally $(d l T)$, and ventrally $(v T)$. Dendrites are studded with varicosities particularly distally, at a spacing of approximately $10 \mu \mathrm{m}$. The third ventricle $(V)$, the posterior commissure $(p c)$, and the nucleus tuberis anterior $(T A)$ are indicated. $B$, Camera lucida drawing of dendritic morphology typically found in sexually immature females. Note absence of a pronounced dorsomedial dendritic field and paucity of varicosities. Similar differences in morphology are observed in males but those are not strongly correlated with relative gonadal weight.

all varicosities in the PPn-C and dividing this value by the total length (in $\mathrm{mm}$ ) of found PPn-C dendrites. Since an accurate measurement of the total dendritic arbor was not possible in heavily labeled nuclei, the second measure could not be obtained in all individuals.

Regardless of whether maturity was induced by simulation of the rainy season or occurred under dry-season conditions, mature females (maturity coefficient, $\mathrm{MC}, \geq 0.095$ ) possessed more varicosities per cell body and showed a higher density of varicosities per unit length of dendrite than did immature females, defined by an MC $\leq 0.070$ (Fig. 4 , top diagram). On the average, immature females had 6 varicosities/soma ( $n=7$ fish) and a density of 4 varicosities $/ \mathrm{mm}$ of dendrite ( $n=4$ fish) compared with 31 varicosities/soma ( $n=10$ fish) and a density of 34 varicosities $/ \mathrm{mm}(n=4$ fish) in mature females. Both differences are significant (varicosities/soma: $p<0.001$; density of varicosities: $p=0.028$; Mann-Whitney $U$ test, 2-tailed). The correlation between the $\mathrm{MC}$ and the number of varicosities per soma is $r_{s}=0.764$ ( $p<0.001,2$-tailed), the correlation between the MC and the density of varicosities is $r_{s}=0.794(p<0.05$, 2-tailed).

Such a clear correlation between the abundance of varicosities and sexual maturity was not found in males (Fig. 4, bottom diagram). Immature males $\left(\mathrm{MC} \leq 3.9 \times 10^{-3}\right) \mathrm{had}$, on the average, 10 varicosities/soma ( $n=8$ fish) and a density of 13 varicosities $/ \mathrm{mm}$ of dendrite ( $n=3 \mathrm{fish}$ ). In mature males (MC $\left.\geq 4.2 \times 10^{-3}\right)$, we found 28 varicosities/soma $(n=7 \mathrm{fish})$ and a varicosity density of $20 / \mathrm{mm}$ ( $n=4$ fish). Both differences between mature and immature males are not significant at the $5 \%$ level. The correlation between the MC and the number of varicosities per soma was $r_{s}=0.089(n=15$, not significant at the $5 \%$ level); the $r_{s}$ between MC and the density of varicosities was $0.071(n=7$, not significant at the $5 \%$ level).

A comparison of the diagrams in Figure 4 shows that the 


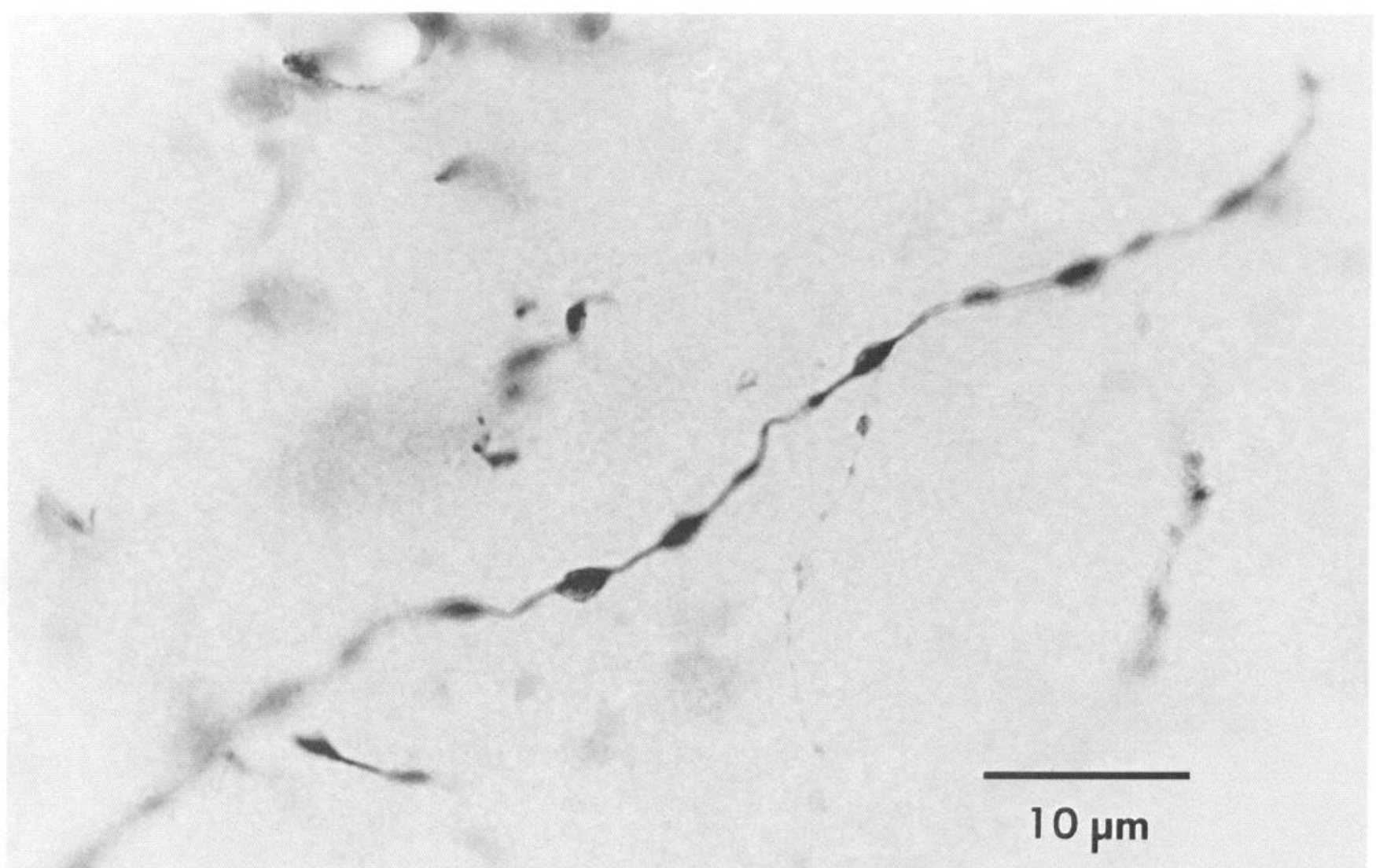

Figure 3. Photomicrograph of an HRP-filled distal dendrite with varicosities.

abundance of varicosities is in the same range in males and females. While immature males, in contrast to immature females, exhibited a considerable variability in the occurrence of varicose dendrites, no mature male and no mature female showed an average of fewer than 4 varicosities per labeled soma. Half of the immature females and immature males had fewer varicosities. This suggests similar structural correlates for chirping in both sexes.

\section{Effect of the termination of the rainy season}

Since Eigenmannia spawns only during the rainy seasons and shows gonadal regression in the intervening dry season, one might also expect reversible concurrent changes in dendritic morphology. To test this assumption, males and females of different ages were kept under rainy-season conditions for several weeks and then observed in a subsequent simulation of the dry season. Animals were injected with HRP and sacrificed at different periods after the end of the rainy-season conditions. The MCs of the most gravid female and the most mature male ever observed in a rainy season were normalized to 1 ; this allowed a comparison of the sexual maturity of males and females within one graph (Fig. 5).

In a period from 4 to 20 weeks after the onset of the dry season, the relative gonadal weight was smaller in regressed animals than in mature fish in the rainy season $(p<0.001$, Mann-Whitney $U$ test, 2-tailed; $n=6$ mature fish in the rainy season, $n=8$ regressed fish in the dry season). A slight increase in relative gonadal weight, however, could be observed after 20 weeks (Fig. 5, bottom diagram). Also, the abundance of dendritic varicosities was reduced in regressed animals; this change in neuronal morphology of the PPn appeared to follow the gonadal regression with some delay after the end of the rainy season (Fig. 5, top diagram). When we compared rainy-season fish with fish in the 4th week after the onset of the dry season, no significant difference at $p<0.05$ (Mann-Whitney $U$ test, 2-tailed) was seen in the density of their varicosities. When we compared rainy-season fish with those from a period between 6 and 20 weeks after the onset of the dry season, however, we found a large variation in the abundance of varicosities, and the mean number of varicosities per labeled soma was significantly smaller in regressed dry-season individuals ( $p=0.004$, Mann-Whitney $U$ test, 2-tailed; $n=6$ mature fish in the rainy season, $n=$ 5 regressed fish in the dry season).

The reduction in the number of varicosities in regressing fish was accompanied by a decrease in their diameter. In 4 males, 2 fish living in the rainy season and 2 fish taken at 4 and 6 weeks, respectively, after the onset of the dry season, we compared the distribution of the size classes of dendritic varicosities after measuring the widths of all varicosities found in the PPn-C (Fig. 6). In the animal sacrificed 4 weeks after the onset of the dry season, no change in the distribution of the size classes of varicosities could yet be observed. In the animal sampled after 6 weeks, however, a clear shift to dendritic swellings of smaller average size was observed. Similar results were found in females at various stages of the dry season. 


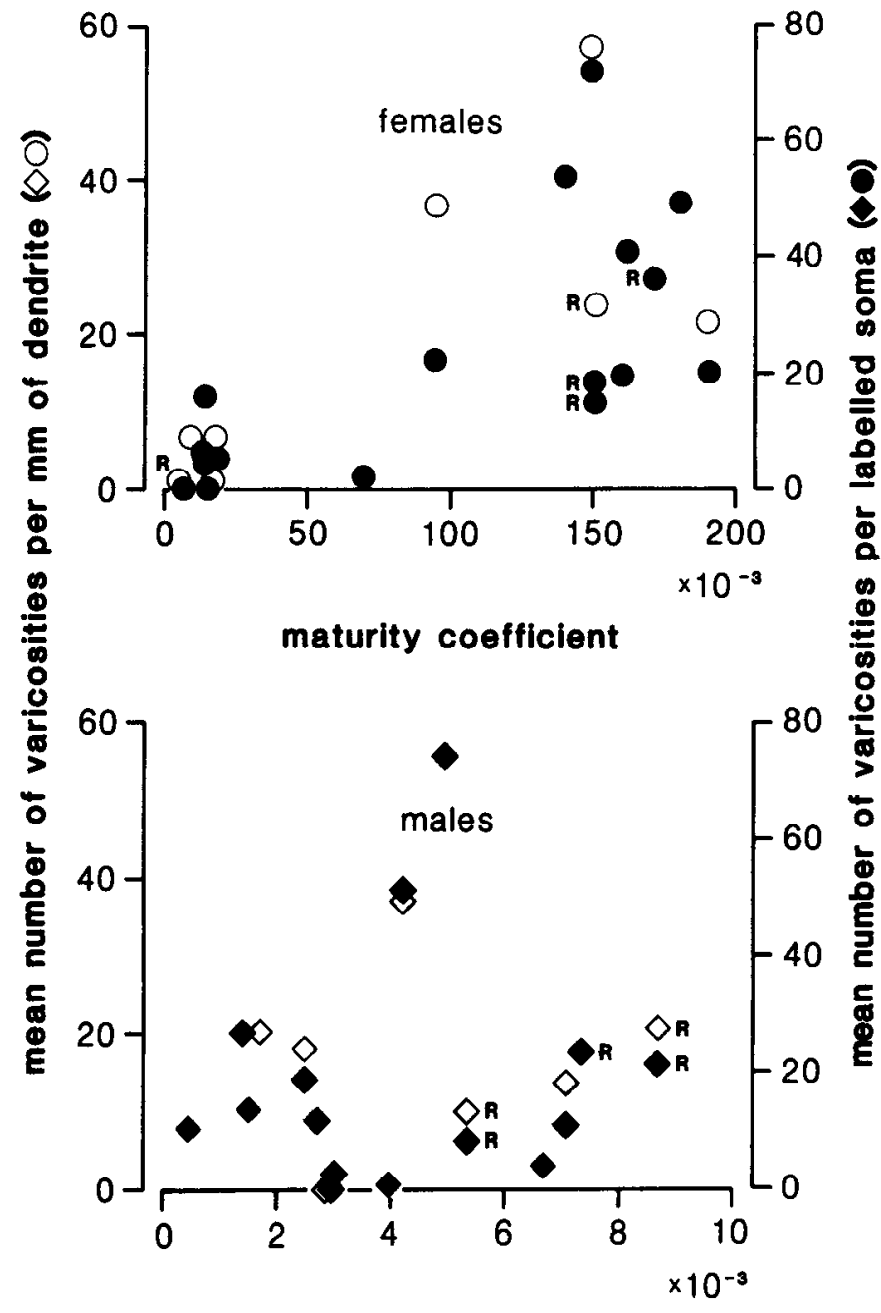

maturity coefficient

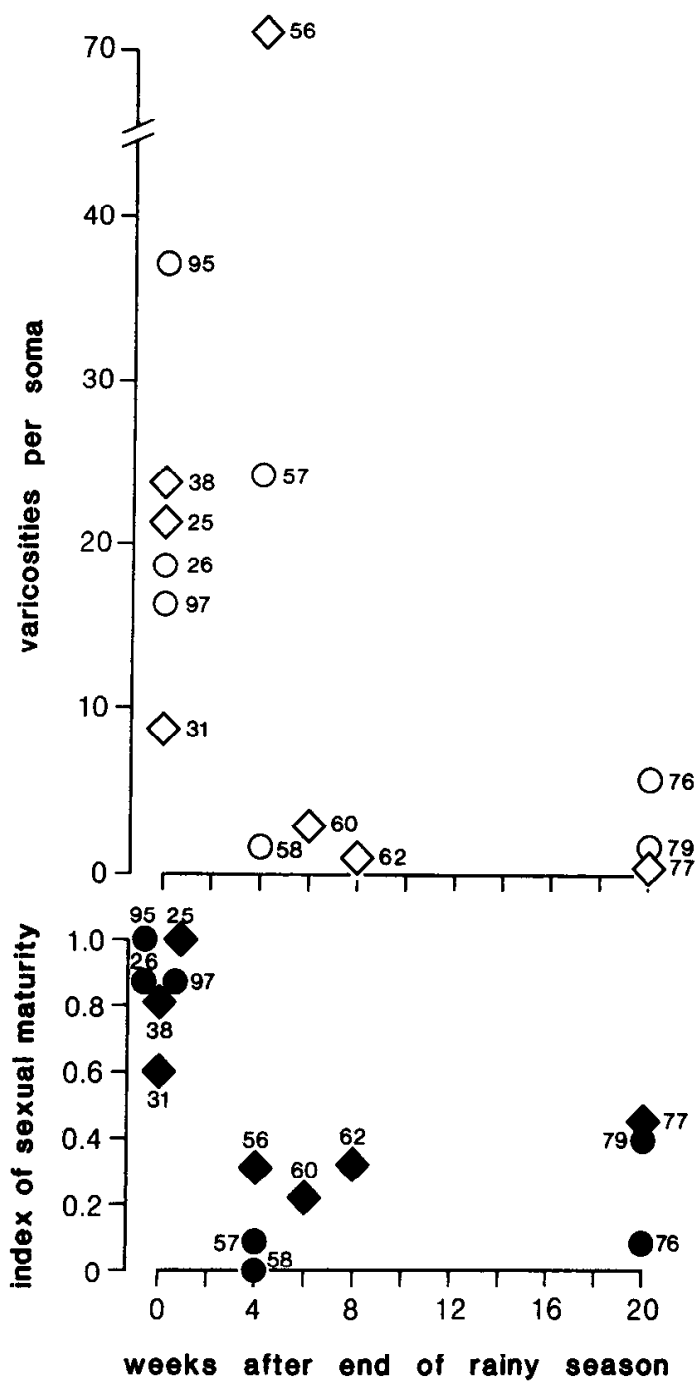

Figure 5. The effect of the termination of the rainy season and the onset of the dry season on the relative gonadal weight (bottom panel) and the mean number of varicosities per labeled soma (top panel) in males (diamonds) and females (circles). The maturity coefficients of the most gravid female $(\mathrm{MC}=0.17)$ and the most mature male $(\mathrm{MC}=8.7$ $\times 10^{-3}$ ) were normalized to 1 . Each fish had been under rainy-season conditions for several weeks before the simulation of the dry season started. Animals were killed at different times after the end of the rainy season. "Zero" on the abscissa indicates fish that were still in the rainy season (symbols in lower panel were slightly displaced to avoid crowding). The termination of the rainy season leads to a rapid reduction in relative gonadal weight. This shrinkage of the gonads lasts for months. Even after 20 weeks of dry-season conditions, the relative gonadal weight is still smaller than in mature animals in the rainy season. Reduction of the abundance of dendritic varicosities appears to follow the gonadal regression with some delay after the end of the rainy season. Numbers near symbols identify specific individuals. Same identification has been used in Figure 6.

ameter in the region of the PPn, we normalized the mean dendritic length per soma to make it independent of brain size. Since an accurate reconstruction and measurement of dendritic sections is only possible if not too many cell bodies and neuronal processes are labeled, we excluded all cases in which more than 25 somata with dendrites were labeled bilaterally. This reduced the number of available cases by approximately $70 \%$.

In females, the mean length of the dendritic arbor per cell body was $880 \mu \mathrm{m}$ in immature fish (mean $\mathrm{MC}=0.012 ; n=4$ ) a measure of the mean total length of the dendritic arbor per cell soma. By then dividing this value by the mean brain di-

\section{Changes in the length of the dendritic arbor} brain nuclei involved in the control of avian song increase their size during the breeding season (DeVoogd and Nottebohm, 1981 Nottebohm, 1981). We expected similar sexual maturity-dependent changes in the morphology of the PPn in Eigenmannia. We measured the total length of all labeled dendritic branches and divided it by the number of cell bodies that were labeled sufficiently well to reveal dendritic processes. We thus obtained 


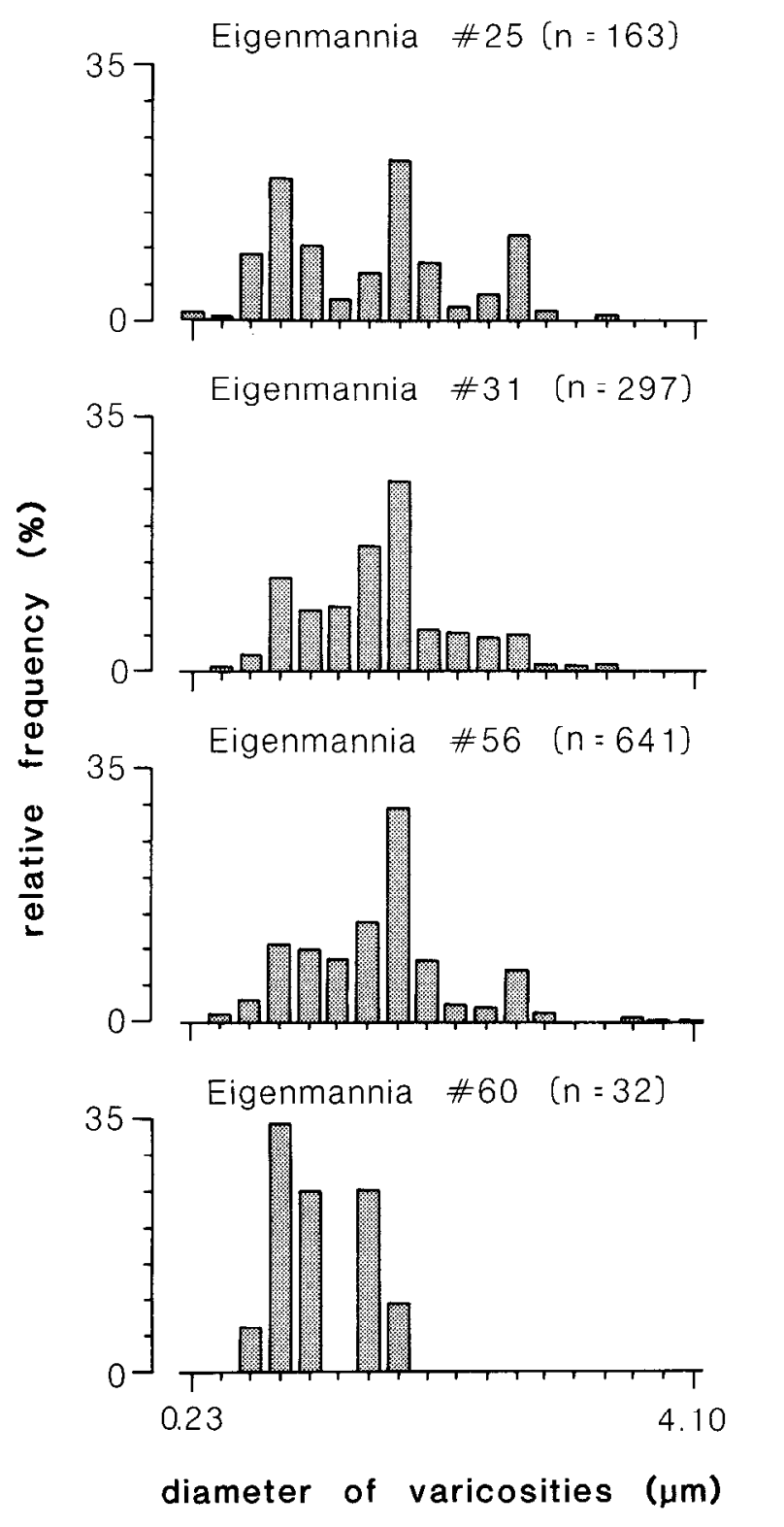

Figure 6. Comparison in the distribution of the size classes of dendritic varicosities in the PPn between mature males under rainy-season conditions and regressed males under dry-season conditions. Eigenmannia $\# 25\left(\mathrm{MC}=8.7 \times 10^{-3}\right)$ and $\# 31\left(\mathrm{MC}=5.2 \times 10^{-3}\right)$ were kept for 4 and 6 weeks, respectively, under rainy-season conditions before they were killed. Eigenmannia $\# 56\left(\mathrm{MC}=2.7 \times 10^{-3}\right)$ and $\# 60(\mathrm{MC}=1.9$ $\left.\times 10^{-3}\right)$ had been under rainy-season conditions for several weeks and were killed 4 and 6 weeks, respectively, after the onset of the dry season. In each fish, the maximal diameter of every varicosity in the PPn was measured at $1000 \times$ under oil immersion. $n$ indicates the total number of varicosities counted bilaterally. While after 4 weeks (\#56) still no change in the distribution of the size classes was found, a shift to varicosities of smaller size, with a concomitant reduction in their total number, was observed after 6 weeks (\#60).

and $1150 \mu \mathrm{m}$ in mature fish (mean $\mathrm{MC}=0.17 ; n=2$ ). The respective normalized measures were 0.330 in immature females and 0.400 in mature females. The data of individual fish are shown in Table 1 . In both groups, nearly the same mean number of somata were labeled (immature: 14; mature: 15). The average estimated amount of HRP injected was found to be smaller in mature females (34 $\mu \mathrm{A} \cdot \mathrm{min})$ than in immature females $(45 \mu \mathrm{A} \cdot \mathrm{min})$, which argues against the possibility that the

\begin{tabular}{|c|c|c|c|c|c|c|}
\hline $\begin{array}{l}\text { Fish } \\
\text { no. }\end{array}$ & Sex & $\mathrm{MC}$ & $\begin{array}{l}\text { MLDS } \\
(\mu \mathrm{m})\end{array}$ & NMLDS & $\begin{array}{l}\text { Somata } \\
\text { labeled } \\
(n)\end{array}$ & $\begin{array}{l}\text { HRP } \\
\text { amount } \\
(\mu \mathrm{A} \cdot \\
\text { min) } \\
\end{array}$ \\
\hline 70 & $\mathbf{M}$ & 0.0025 & 1003 & 0.332 & 9 & 45 \\
\hline 36 & M & 0.0029 & 605 & 0.242 & 23 & 60 \\
\hline 69 & $\mathbf{M}$ & 0.0042 & 1400 & 0.459 & 17 & 45 \\
\hline 67 & $\mathbf{M}$ & 0.0071 & 796 & 0.353 & 12 & 68 \\
\hline 25 & $\mathbf{M}$ & 0.0087 & 1040 & 0.290 & 10 & 20 \\
\hline 41 & $\mathrm{~F}$ & 0.0051 & 882 & 0.280 & 5 & 15 \\
\hline 65 & $F$ & 0.0139 & 844 & 0.359 & 19 & 60 \\
\hline 68 & $\mathrm{~F}$ & 0.0144 & 1108 & 0.422 & 9 & 60 \\
\hline 32 & $\mathrm{~F}$ & 0.0150 & 678 & 0.251 & 23 & 45 \\
\hline 72 & $\mathrm{~F}$ & 0.1447 & 1307 & 0.443 & 15 & 53 \\
\hline 19 & $\mathrm{~F}$ & 0.1917 & 984 & 0.362 & 15 & 15 \\
\hline
\end{tabular}

M, male; F, female; MC, maturity coefficient; MLDS, mean length of dendrites per labeled soma; NMLDS, normalized mean length of dendrites per labeled soma.

longer dendritic arbor in mature females could be due to stronger injections of HRP. Both measurements of the dendritic arbor indicate that the overall length of the dendritic processes was 20-30\% larger in mature females than in immature females. This assumption is also supported by the Spearman's rank correlation coefficient: the $r_{s}$ between MC and the mean length of the dendritic arbor per cell body was 0.290 , and the $r_{s}$ between $\mathrm{MC}$ and the normalized length measure was 0.377 ; neither result, however, was statistically significant at a level lower than $5 \%$.

We found similar differences between immature and mature males as we had observed in females (Table 1). The mean length of the dendritic arbor per cell body was $800 \mu \mathrm{m}$ in immature fish (mean MC $=2.7 \times 10^{-3} ; n=2$ fish) and $1080 \mu \mathrm{m}$ in mature fish (mean MC $6.7 \times 10^{-3} ; n=3$ fish). The normalized measures were 0.290 and 0.370 , respectively. This suggests that the dendritic arbor was approximately $30 \%$ longer in mature males than in immature males. The observed differences cannot be explained on the basis of different numbers of somata or different amounts of HRP injected (immature males: 16 somata, $53 \mu \mathrm{A}$. min HRP; mature males: 13 somata, $44 \mu \mathrm{A} \cdot \min$ HRP). The correlation between sexual maturity and both measurements of dendritic length is positive: the $r_{s}$ between the $\mathrm{MC}$ and the mean length of the dendritic arbor per cell body is 0.300 , and the $r_{s}$ between the $\mathrm{MC}$ and the normalized length is 0.100 ; neither result, however, was statistically significant at a level lower than $5 \%$.

Is the trend toward increase in the length of the dendritic arbor during sexual maturation reversible? Preliminary observations seem to support this possibility. Three males had been kept under rainy-season conditions for several weeks and were then subjected to a subsequent simulation of the dry season. They were sacrificed after 4 (\#56), 6 (\#60), and 8 weeks ( $\# 62$ ) of being in the dry season. In all 3 fish, the number of labeled somata was similar (\#56: 9; \#60: 11; \#62: 7). The amount of HRP injected was $48 \mu \mathrm{A} \cdot \min$ in \#56, $23 \mu \mathrm{A} \cdot \min$ in \#60, and 23 $\mu \mathrm{A} \cdot \mathrm{min}$ in \#62. The 3 individuals showed the following mean lengths of the dendritic arbor (in parentheses the normalized measure): fish \#56, $2110 \mu \mathrm{m}(0.600)$; fish $\# 60,950 \mu \mathrm{m}(0.290)$; fish $\# 62,530 \mu \mathrm{m}(0.170)$. These data indicate a strong reduction 
Figure 7. Mean length of dendritic arbors of individually reconstructed multipolar neurons in the PPn-C of immature (mean $\mathrm{MC}=0.01$ ) and mature females (mean $\mathrm{MC}=0.16$ ) in Eigenmannia. In each group, 5 neurons were reconstructed from different fish. The vertical lines at each bar indicate the range of individual data. Dendritic territories were defined as shown in the insert and described in the text. The increase in overall length (total) by approximately $40 \%$ during sexual maturation is due to a significant proliferation in the dorsomedial territory $(d m T)$, whereas the dendritic lengths of the ventral territory $(v T)$ and the dorsolateral territory $(d l T)$ are not significantly different in mature and immature females.

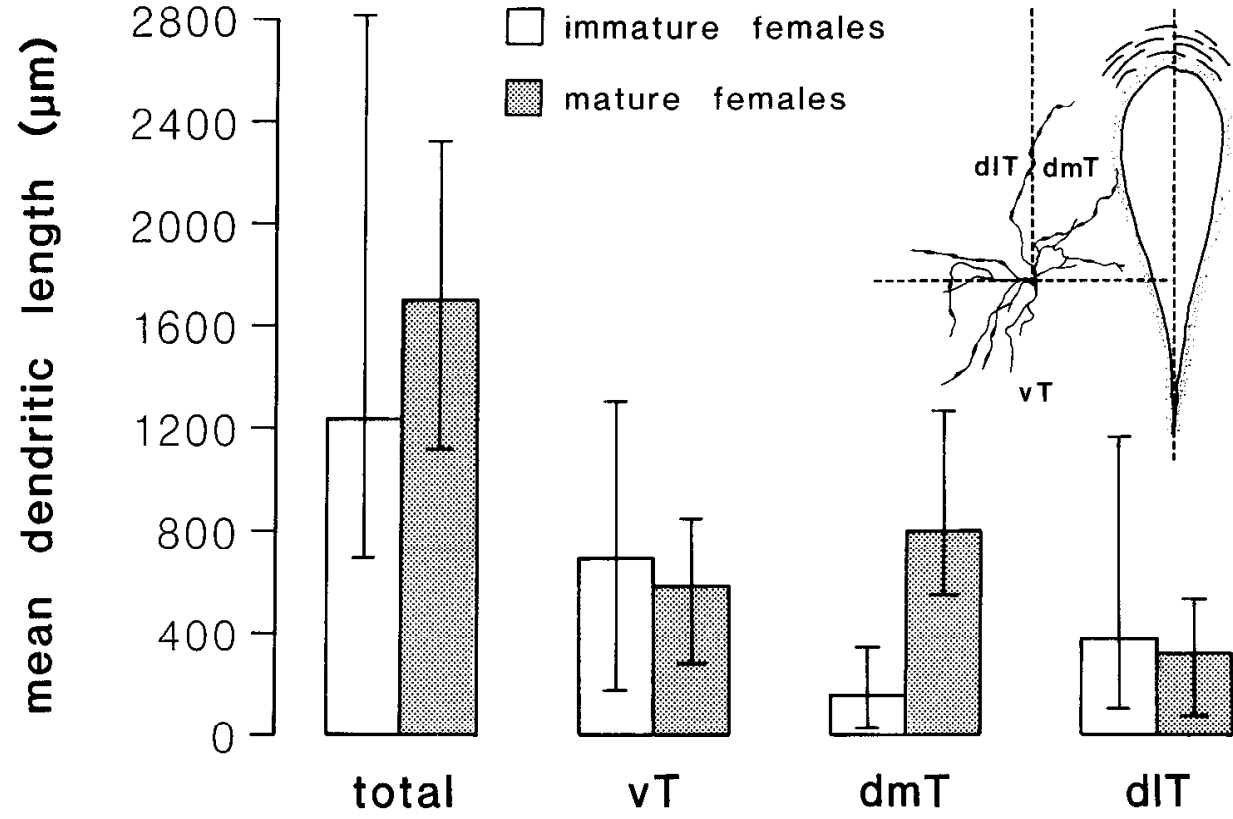

by measuring the total length of all labeled dendritic branches (see above, "Changes in the lengths of the dendritic arbors"). This is due to the fact that in the former case the most heavily labeled neuron in each animal was chosen, whereas in the latter case neurons with incompletely filled dendrites were included. A significant change was found in the pattern of dendritic proliferation of individual PPn-C neurons: while immature females showed only little invasion of the dorsomcdial tcrritory, almost half of the total dendritic arbor was located in this field in mature females (Fig. 7). This difference in the occupation of the dorsomedial territory is significant at $p=0.008$ (Mann-Whitney $U$ test, 2-tailed). We observed no significant alteration in dendritic proliferation in the ventral and dorsolateral territory. Dendrites thus appear to grow in the dorsomedial field during sexual maturation, whereas they remain constant in the ventral and dorsolateral territory.

\section{Discussion}

This study has demonstrated that individual dendrites of the large multipolar cells in the PPn of female Eigenmannia develop and regress in concert with the seasonal recrudescence and regression of the fish's ovaries. Most significantly, the distal portions of their dendrites, presumably zones of growth, show an abundance of varicosities in mature individuals (Figs. 1-4). Mature females showed pronounced varicose dendrites invading the dorsomedial field in the vicinity of the posterior commissure and the underlying ventricle (Figs. $2 A, 7$ ). A similar plasticity in dendritic development was also seen in males, although the relative weight of the gonads in adult and juvenile individuals was not found to be correlated with dendritic growth. Nevertheless, males showed abundant varicosities during the simulated rainy season, the time of breeding, while males showed few varicosities over several weeks during the following simulated dry season, when breeding had ceased (Figs. 5, 6).

\section{HRP labeling}

The results of our study with retrograde labeling, however, must be interpreted with caution. Because of variable clogging of the electrodes, it was impossible to inject standardized quantities females as well as of immature females were much larger than the lengths of the mean dendritic arbors per cell body obtained 
of HRP into the medullary pacemaker. Moreover, the quality of the HRP and the degree of its uptake appeared to vary between batches. In some animals, only a single PPn neuron was labeled sufficiently well that its dendrites could be traced over a longer distance. In most instances, the label faded gradually along the course of the dendrites, and such neurons, therefore, could not be reconstructed completely. Nevertheless, we still were able to count varicosities in all visible sections of dendrites.

One could argue that the mature females in our sample might have obtained larger injections of HRP and, therefore, revealed more extensive dendritic branching and a larger number of varicosities. In order to test this hypothesis, we estimated the quantity of HRP applied to the pacemaker by the product of mean current intensity and duration of injection. We found a weak negative correlation $\left(r_{s}=-0.208, n=17\right.$ fish, not significant at $p<0.05,2$-tailed) between this estimated HRP quantity and the $\mathrm{MC}$ of the females. This negative correlation argues against this hypothesis and reflects our tendency to inject smaller amounts of HRP into the pacemaker of mature specimens. Moreover, the estimated HRP quantity and the degree of transport of HRP appear to be poorly correlated. In 11 cases in which we had penetrated the pacemaker centrally and thus avoided a major spill of HRP into the surrounding medulla, we found a rank correlation of -0.009 between the estimated amount of HRP and the number of PPn somata with clearly visible processes. On the other hand, the maturity of the animal appears to have a minor influence upon the uptake of HRP. In the same 11 females in which we had injected the HRP centrally into the pacemaker, a rank correlation between maturity coefficient and number of strongly labeled PPn cell somata yielded an $r_{s}$ of 0.130 (not significant at $p<0.05,2$-tailed). Mature females, therefore, showed a weak tendency for stronger uptake of HRP. We cannot exclude the possibility that this tendency contributed to the slightly higher average length of the dendritic arbor measured in mature females. It cannot, however, explain the dramatic differences in the abundance of varicosities between mature and immature females.

\section{Changes in length and distribution of dendrites}

In contrast to the drastic changes in the abundance of varicosities, we found only minor differences in the mean total length of the dendritic arbor between mature and immature individuals. This agrees with the absence of significant maturity-related differences in the total length of dendrites of reconstructed individual neurons. The latter fact, however, does not exclude the possibility that only a certain percentage of dendritic arbors in the PPn-C grows and regresses in concert with the seasonal changes of the fish's ovaries. On the other hand, significant differences were found in the invasion of dendritic territories of individual PPn-C neurons of mature and immature females. Dendrites appear to grow only in the dorsomedial territory and remain constant or decrease slightly in other territories. The total length would thus increase only slightly.

\section{Synchronization of neuronal and gonadal development}

We were surprised to find relative gonadal weight to be a good predictor for dendritic development only in females. This suggests that the factors controlling testicular development and dendritic growth in males are not strongly related. Such factors could be gonadotropin-releasing hormones, gonadotropin release-inhibitory factors, gonadotropins, and/or gonadal steroids. In the Atlantic salmon, Salmo salar, for example, Stuart-Kregor et al. (1981) found higher levels of testosterone in males that had not begun spermiation $(22 \mathrm{ngm} / \mathrm{ml})$ than in "ripe" males $(5.2 \mathrm{ngm} / \mathrm{ml})$. And in Gobius niger, another teleost, 2 maxima of testosterone level have been recorded, one before and one during the breeding season (Bonnin, 1979). On the other hand, our fish go through cycles of sexual maturation even without priming by the onset of the rainy season, particularly if they receive high-protein food and when dry-season conditions persist too long. Our studies of males over the beginning of a dry season following a rainy season indicated, however, that testicles regressed more rapidly than dendritic varicosities. In view of those spontaneously occurring cycles of maturation, such time lags could account for the poor correlation observed between testicular and neuronal development. Future, accurate assessments of hormonal titers might yield more reliable predictors of neuronal development.

\section{Seasonal neuronal modifications and chirping behavior}

The large multipolar neurons are known to generate "chirps" (Kawasaki and Heiligenberg, 1988, Kawasaki et al., 1988), a social electric signal used during courtship and reproductive behavior. The conditions of the rainy season, therefore, not only induce a seasonal gonadal maturation and the expression of courtship and mating behaviors (Hopkins, 1974; Kirschbaum, 1975, 1979; Hagedorn and Heiligenberg, 1985), but also modify a neuronal system responsible for the production of one of these behaviors.

Chirping is an abrupt, transient acceleration, often followed by a brief interruption of the EOD. Sexually mature and territorial animals commonly chirp in response to the electric signals of intruders or potential mates, while immature animals never respond to signals of a conspecific in this manner. Chirping, however, can be reliably elicited by electrical or chemical stimulation of the multipolar cells in the PPn in any postjuvenile animal, regardless of its reproductive state (Kawasaki et al., 1988). The capacity for producing this motor pattern, therefore, is always present, independently of the state of sexual maturation. Why then does Eigenmannia chirp in response to the presence of conspecifics only during the reproductive season?

Recordings within the complex of the diencephalic nucleus electrosensorius have revealed a variety of types of neurons that respond to electric signals of neighbors (Bastian and Yuthas, 1984; Keller, 1988). Some of these neurons even fire specifically in response to chirp-like modulations of a neighbor's signal. These various types of neurons are also responsive in immature animals so that one may safely assume that Eigenmannia can detect chirps produced by neighbors even if the animal itself is not disposed to respond with chirps. The complex of the nucleus electrosensorius sends axons into the PPn and its vicinity with dense innervation of the dorsomedial territory defined by PPn-C dendrites (C. H. Keller, personal communication). Such a connection might link the perception of social electric signals with their production. Therefore, one might propose at this point that the growth of dendrites of the multipolar cells in the PPn enhances the establishment of synaptic contacts with afferent neurons coding the perception of social signals.

This structural modification might complement an additional facilitatory role of neuromodulators whose supply to PPn-C neurons might be enhanced by growing PPn-C dendrites and varicosities. The presence of 3 dendritic territories of PPn-C cells may also be correlated with different transmitters or modulators in different dendritic branches. A number of neuroactive 
peptides appears to be present in the PPn. Their peptidergic axons may differentially project to the various dendritic territories of the PPn-C. The dorsomedial territory in the gymnotiform Apteronotus leptorhynchus, for example, appears to receive an especially dense somatostatin innervation, whereas substance $\mathbf{P}$ seems to predominate in the ventral territory (Sas and Maler, 1988; L. Maler, personal communication). The different distribution of these neuropeptides may indicate different functional roles of the dendritic territories. Modulatory effects of monamines on chirping have already been shown in $A$. leptorhynchus: while injection of serotonin (5-hydroxytryptamine, 5-HT) into the ventricle briefly inhibited chirping, noradrenalin enhanced this behavior pattern (Maler and Ellis, 1987). This is in agreement with the finding that methysergide, a 5-HT receptor antagonist, as well as fluoxetine and citalopram, 5-HT uptake inhibitors, significantly increased chirping. Immunohistochemical brain mapping of 5-HT showed labeled nerve terminals in the PPn (Johnston et al., 1988).

As mentioned initially, the most dramatic seasonal morphological change seen during the dendritic growth of the multipolar cells of the PPn is the appearance of strings of varicosities. Our preliminary ultrastructural studies have revealed an abundance of chemical synapses contacting these varicosities. Similar synapses, however, are also encountered on the normal, slender sections of these dendrites. Quantitative ultrastructural studies as well as immunohistochemical analyses of these neurons and their afferent connections should reveal many more details of their seasonal reorganization.

\section{Comparisons with other studies}

Varicositics arc also found in other brain regions of Eigenmannia (personal observations). In the rat, dendritic varicosities have been described in the lateral vestibular nucleus and, less extensively, in the cerebellar cortex, the hypothalamus, and the superior cervical ganglion (Sotelo and Palay, 1968; Peters et al., 1976, p. 88 ). The swellings in the lateral vestibular nucleus vary from 1 to $8 \mu \mathrm{m}$ in diameter and are most abundant on the tips or the distal segments of dendrites in the dorsal part of the nucleus. In nearly every instance, axonal terminals synapse upon them. These dendritic varicosities contain a very large number of long, slender mitochondria with longitudinally oriented cristae and glycogen particles. We suggest that such varicosities could represent growing or expanding tips of developing or regenerating nerve cells.

On the evidence available, it seems reasonable to assume that the dendritic development of the PPn-C neurons is directly or indirectly controlled by the same factors that regulate gonadal recrudescence. Such factors could be gonadotropin-releasing hormones, gonadotropin release-inhibitory factors, gonadotropins, and/or gonadal steroids. These may not necessarily act on PPn-C neurons directly as their effect may be mediated by other cells. In common canaries (Serinus canaria), seasonal changes in the production of songs and in the underlying neuronal structure of song control areas in the telencephalon might depend on testosterone and its androgenic and estrogenic metabolites (Nottebohm, 1981, 1986; Arnold, 1985; Arnold and Breedlove, 1985; Bottjer et al., 1986; DeVoogd, 1986; Nottebohm et al., 1987). One nucleus, the Area X, shows hormone-dependent alterations in the neuronal morphology, although it lacks steroid-binding cells. Hormonal effects, however, may instead be mediated by estrogen-sensitive cells of a different region, the nucleus hyperstriatalis pars caudale, which projects to Area X (Gahr, 1988).
A similar proliferation of dendrites as observed in the avian forebrain and the PPn of Eigenmannia was also found in motoneurons controlling the penis muscles in white-footed mice (Peromyscus leucopus), seasonal breeders that exhibit marked fluctuations in reproductive behavior (Forger and Breedlove, 1987). It may thus be a common principle that seasonal modulations in an animal's propensity to execute specific behaviors may partly be caused by morphological changes of neuronal network involved in the control of these behaviors.

\section{References}

Adams, J. C. (1981) Heavy metal intensification of DAB-based HRP reaction product. J. Histochem. Cytochem. 29: 775.

Arnold, A. P. (1985) Gonadal steroid-induced organization and reorganization of neural circuits involved in bird song. In Synaptic Plasticity, C. W. Cotman, ed., pp. 263-285, Guilford, New York.

Arnold, A. P., and S. M. Breedlove (1985) Organizational and activational effects of sex steroids on brain and behavior: A reanalysis. Horm. Behav. 19: 469-498.

Bastian, J., and J. Yuthas (1984) The jamming avoidance response of Eigenmannia: Properties of a diencephalic link betwecn sensory processing and motor output. J. Comp. Physiol. 154: 895-908.

Bennett, M. V. L. (1971) Electric organs. In Fish Physiology, W.S. Hoar and D.J. Randall, eds., pp. 493-574, Academic, New York.

Bonnin, J. P. (1979) Variations saisonnières de la testosterone plasmatique chez un poisson téléostéen, Gobius niger. C. R. Hebd. Séances Acad. Sci. Ser D 288: 627-630.

Bottjer, S. W., J. N. Schoonmaker, and A. P. Arnold (1986) Auditory and hormonal stimulation interact to produce neural growth in adult canaries. J. Neurobiol. 17: 605-612.

DeVoogd, T. J. (1986) Steroid interactions with structure and function of avian song regions. J. Neurobiol. 17: 177-201.

DeVoogd, T. J., and F. Nottebohm (1981) Gonadal hormones induce dendritic growth in the adult avian brain. Science 214: 202-204.

Forger, N. G., and S. M. Breedlove (1987) Seasonal variation in mammalian striated muscle mass and motoneuron morphology. J. Neurobiol. 18: 155-165.

Gahr, M. (1988) The implication of estrogen sensitive neurons for the plasticity of the neural song control system of adult canaries (Abstr.). 20th Annual Meeting of the European Brain and Behaviour Society, 7-9 September 1988 in Zürich/Switzerland.

Hagedorn, M., and W. Heiligenberg (1985) Court and spark: Electric signals in the courtship and mating of gymnotoid fish. Anim. Behav. 33: 254-265.

Heiligenberg, W., T. Finger, J. Matsubara, and C. Carr (1981) Input to the medullary pacemaker nucleus in the weakly electric fish, $E i$ genmannia (Sternopygidae, Gymnotiformes). Brain Res. 211: 418423

Hopkins, C. D. (1974) Electric communication: Functions in the social behavior of Eigenmannia virescens. Behaviour 50: 270-305.

Johnston, S., L. Maler, and B. Tinner (1988) 5HT distribution in Apteronotus leptorhynchus brain and relation to male social behavior. Soc. Neurosci. Abstr. 14: 691.

Kawasaki, M., and W. Heiligenberg (1988) Individual prepacemaker neurons can modulate the pacemaker cycle of the gymnotiform electric fish, Eigenmannia. J. Comp. Physiol. 162: 13-21.

Kawasaki, M., L. Maler, G. J. Rose, and W. Heiligenberg (1988) The anatomical and functional organization of the prepacemaker nucleus in gymnotiform electric fish: The accommodation of two behaviors in one nucleus. J. Comp. Neurol. 276:113-131.

Keller, C. H. (1988) Stimulus discrimination in the diencephalon of Eigenmannia: The emergence and sharpening of a sensory filter. $\mathrm{J}$. Comp. Physiol. 162: 747-757.

Kirschbaum, F. (1975) Environmental factors control the periodical reproduction of tropical electric fish. Experientia 31: 1159-1160.

Kirschbaum, F, (1979) Reproduction of the weakly electric fish $E i$ genmannia virescens (Rhamphichtyidae, Teleostei) in captivity. I. Control of gonadal recrudescence and regression by environmental factors. Behav. Ecol. Sociobiol. 4: 331-355.

Leyhausen, C., F. Kirschbaum, T. Szabo, and M. Erdelen (1987) Differential growth in the brain of the weakly electric fish, Apteronotus leptorhynchus (Gymnotiformes), during ontogenesis. Brain Behav. Evol. 30: 230-248. 
Lundquist, J., and J. Josefsson (1971) Sensitive method for determination of peroxidase activity in tissue by means of coupled oxidation reaction. Anal. Biochem. 41: 567-577.

Maler, L., and W. G. Ellis (1987) Inter-male aggressive signals in weakly electric fish are modulated by monoamines. Behav. Brain Res. 25: 75-81.

Mannen, H. (1966) Contribution to the morphological study of dendritic arborization in the brain stem. In Correlative Neurosciences, $T$. Tokizane and J. P. Schade, eds., pp. 131-162, Elsevier, New York.

Metcalfe, W. K. (1985) Sensory neuron growth cones comigrate with posterior lateral line primordial cells in zebrafish. J. Comp. Neurol. 238: 218-224.

Nottebohm, F. (1981) A brain for all seasons: Cyclical anatomical changes in song control nuclei of the canary brain. Science $214: 1368-$ 1370 .

Nottebohm, F. (1986) Birdsong as a model in which to study brain processes related to learning. The Condor 86: 227-236.

Nottebohm, F., M. E. Nottebohm, L. A. Crane, and J. C. Wingfield (1987) Seasonal changes in gonadal hormone levels of adult male canaries and their relation to song. Behav. Neurol. Biol. 47: 197-211.

Peters, A., S. L. Palay, and H. de F. Webster (1976) The Fine Structure of the Nervous System: The Neurons and Supporting Cells. W. B. Saunders, Philadelphia.
Rose, G. J., M. Kawasaki, and W. Heiligenberg (1988) "Recognition units" at the top of a neuronal hierarchy? Prepacemaker neurons in Eigenmannia code the sign of frequency differences unambiguously. J. Comp. Physiol. 162: 759-772.

Sas, E., and L. Maler (1988) Somatostatin immunoreactivity in the brain of a gymnotid teleost fish. Soc. Neurosci. Abstr. 14: 985.

Siegel, S. (1956) Nonparametric Statistics for the Behavioral Sciences. McGraw-Hill, New York.

Sotelo, C., and S. L. Palay (1968) The fine structure of the lateral vestibular nucleus in the rat. I. Neurons and neuroglial cells. J. Cell Biol. 36: 151-179.

Stuart-Kregor, P. A. D., J. P. Sumpter, and J. M. Dodd (1981) The involvement of gonadotropin and sex steroids in the control of reproduction in the parr and adults of Atlantic salmon, Salmo salar L. J. Fish. Biol. 18: 59-72.

Zupanc, G. K. H., and W. Heiligenberg (1988a) Sexual maturitydependent neural plasticity in the prepacemaker nucleus of adult knifefish. Soc. Neurosci. Abstr. 14: 606.

Zupanc, G. K. H., and W. Heiligenberg (1988b) Sexual maturitydependent neural plasticity in the prepacemaker nucleus of adult weakly electric knifefish. Am. Zool. 28: 180A. 